\title{
DETERMINATION OF AN OPTIMAL SCOPE OF INSTRUMENTAL EXAMINATIONS DURING CONSTRUCTION AND OPERATION OF BUILDINGS AND STRUCTURES
}

\section{Hryhorovskyi P. Ye.}

\section{INTRODUCTION}

Research into interactions between construction activities, surrounding territories and neighboring developed areas is an urgent problem when natural and man-caused processes are studied and coped with during construction and operation of buildings and structures. Defects and damages of buildings that have not been detected and corrected in good time result in deformations. In addition to material outlays on recovery of structure characteristics their effects are detrimental to the natural and social environment. Therefore the prompt evaluation of building conditions, the forecasting of trends in development of defects and damages and the elaboration of measures on their stabilization or removal are very important. For that a mechanism of destruction and wearing of structural elements during construction and operation activities shall be understood and the opportunity of estimation of effects of environmental factors shall exist. For this purpose the objective data measured and collected with the use of instrumentation are vital.

External factors are classified to natural and man-caused ones. The natural factors include atmospheric, climatic, ground, biological and seismic ones. The atmospheric, biological and ground conditions are of particular interest as for the last decades they are under significant man-caused influence. The work concerns with the principal natural and man-caused factors, in particular, deformations, landslides, underflooding and vibrations that have destructive effects on the operating availability of buildings and structures. The recommendations on determination of an optimal scope of instrumental measurements have been elaborated for such objects that are under construction or operation.

Deformation processes are results of untimely detected defects and damages of building elements. Duration and sizes of defects in an object substantially depend on soil types at its base and types of deformation depend on structural features of buildings. Under the action of building weight and other vertical loads the base soils contract and that results in settlement of the foundation. Soils under foundations have various physical and mechanical properties and sizes of foundation settlements are various as 
their loads are not the same and these differences may result in deformations of construction structures.

Slides of buildings and structures that is their horizontal displacements occur under horizontal loads which also result in deformation of elements. Slides occur when the stability of slopes is disturbed by man-caused or natural processes and when soil cohesion forces are less than the gravity. The rate of sliding of soil masses may be hardly noticeable or up to some meters per second ${ }^{1}$. At that intensification and formation of deep block slides of squeezing and slipping development of smallest surface slides of slipping, visco-plastic flow, hydrodynamic destruction and sudden rarefaction are possible.

Underflooding is a process of natural or man-caused nature that is dangerous for buildings $s^{2,3}$. The man-caused causes of underflooding are as follows: changes in conditions of surface flows during earthwork on vertical grading or backfilling of natural drains and ravines; leaks from water utilities and storm sewages, artificial ponds; disturbances of surface water and groundwater flows, significant breaks between earthwork and construction work; infiltration of process water; decreased evaporation under buildings and pavements; groundwater damming in coastal or riverside areas; barrage effects during construction of buried underground structures.

Negative consequences of underfloodings are related with the following: subsidences and cavities of the earth's surface which are created due to compacting of wetted soils at the bases of buildings; hydrodynamic rarefaction of soils that becomes apparent as soil removals on slopes or soil ejections into construction excavations; creation and intensification of sliding, karst, karst-suffusion, erosion and other geologic dangers with corrosion destruction of building foundations and basements, flooding of cellars, hoistways, underground structures and utilities, terrain swamping.

Vibrations, whose main external source is rail transport (the Metro, tramlines and railways), may significantly exceed the allowable limits. Levels and ranges of vibration frequencies in various points of building depend on a generation source, soil properties and structure characteristics ${ }^{4,5}$. The peak

\footnotetext{
${ }^{1}$ National report on the state of man-caused and natural safety in Ukraine in 2014. The State Emergency Service of Ukraine. Kyiv, 2015

${ }^{2}$ Recommendations on estimation of geological risks in the territory of the city of Moscow

${ }^{3}$ SP 11-105-97 System of normative documents in the construction industry. Code of regulations on engineering surveys for the construction industry. Part II. Regulations on production of work in the regions of development of dangerous geological or engineering and geological processes.

${ }^{4}$ GOST R 52892-2007. Vibration and shock. Vibration of buildings. Measurement of vibration and evaluation of its effects on structure. - M. : Standartinform, 2008.

${ }^{5}$ Osypov O.F. Construction under conditions of urban development. Experience and prospects / O.F. Osypov, I.T. Hladun // Urban and territorial planning : coll. sci.-techn. art. K. : KNUBA, 2004. - No. 12. - P. 9.18.
} 
velocity value is a vibration parameter that correlates with the risk of building structures damages in the best way. This parameter characterizes the energy of seismic waves which affect structures. At the peak velocity value the risk of damage depends on factors related to the frequency spectrum of vibrations. Therefore vibrations are estimated on the basis of the dominant component in the frequency spectrum.

During construction under constrained conditions driving piles and digging foundation pits shall not affect the existing buildings and vibrations shall not exceed the allowable level. The building conditions shall be supervised before, during and after piling work as well as before stabilization of deformations ${ }^{6}$. The most significant loads are dynamic ones due to transport movement. It is difficult to determine a source of the most intensive dynamic load due to a rather wide spread of ranges in which the parameters that cause soil vibrations vary ${ }^{7}$. The scope of instrumental examinations and measurements depends on a vibration source category.

To estimate and ensure serviceability of buildings one shall forecast their life times and frequency of their scheduled repairs or overhauls. The standard service life values for structures are averaged, estimated and related to physical deterioration of materials values. The actual service life is affected by actual operating conditions. To establish changes in absolute or relative parameters, which are developed dynamically and affect the serviceability of buildings and structures, or effects of these parameters on construction projects they shall be recorded with the use of instrumental methods. Therefore the issue of determination of an optimal scope of instrumental examinations during construction and operation of buildings and structures is important.

\section{Algorithm of determination of an optimal scope of instrumental examinations subject to the vulnerability criterion}

Duration of the life cycle of buildings depends on timely accounting of risks of damages and forecasting of deterioration of building operating conditions under effects of external (natural or man-caused) and internal (construction or operational) risks. When the risks of damages are estimated a possible intensification of dangers, capacity and remoteness of a threat source, operating conditions of the building and vulnerability conditions

\footnotetext{
${ }^{6}$ VSN 358-76 Instructions on pile driving near buildings and structures. - M. : TsBNTI, 1976.

7 Dudkin E.S. Dynamic effects of municipal transport movement on buildings and structures / E.S. Dudkin // Polzunov Bulletin. 2007. - No. 1-2. - P. 30-32.
} 
shall be accounted for. In addition, the vulnerability of the building shall be estimated $^{8,9}$.

It has been proposed to consider the vulnerability as a building property to lose serviceability due to a possible damage of the building under effects of negative factors. A degree of vulnerability depends on a totality of conditions of the building, its soil base and surrounding territory. To make a decision on expediency and scope of examinations a classification of building vulnerabilities has been proposed (low, medium and high classes):

- low vulnerability

- low vulnerability

$$
k_{y \sigma} \leq 0,33 \cdot k_{y \max }=0,33,
$$

where $k_{y \max }=1,0$ is maximum possible value of the factor of vulnerability,

- medium vulnerability

$$
0,33>k_{y \sigma}>0,67
$$

- high vulnerability

$$
k_{y \sigma} \geq 0,67,
$$

$k_{y \sigma}$ may take values that exceed 1,0 when coefficients of threat significance or degrees of compliance are taken into account.

A decision on the necessity of examinations, their scope and periodicity are made on the basis of the results obtained during determination of the factors of vulnerability:

- at the low vulnerability of building the scope of examinations is usual i.e. taking into account the low probability of occurrence of damages the instrumental examinations are not necessary and visual examinations will be sufficient;

- at the medium vulnerability the scope of examinations is expanded i.e. taking into account the medium probability of occurrence of damages in

\footnotetext{
${ }^{8}$ Methodic recommendations for estimation of risk and damage at underflooding of territories. - M., 2001.

${ }^{9}$ Mikhailenko V.M., Hryhorovskyi P.Ye., Models and methods of information system for diagnostics of operating conditions of construction projects / V.M. Mikhailenko, I.V. Rusan, P.Ye. Hryhorovskyi, O.O. Terentiev, A.T. Sviderskiy, Ye.V. Horbatiuk. - K. : TsP «Komprynt». - 2018.
} 
addition to the visual inspections the periodic instrumental examinations shall be carried out;

- at the high vulnerability the scope of examinations is special i.e. taking into account the high probability of occurrence of damages, in addition to the necessity of the expanded scope of examinations the automated monitoring shall be carried out.

To determine the scope of instrumental examinations during operation of buildings the following algorithms shall be developed: estimation of risks of damages (determination of the vulnerability) of buildings with regard to threats; selection of methods and measures for inspection of operating conditions of buildings, checked parameters and periodicity of inspections; arrangement of measurements subject to the level of building vulnerability; determination of possible losses due to untimely detection of damages. The algorithm of determination of vulnerability is presented in Fig. 1.

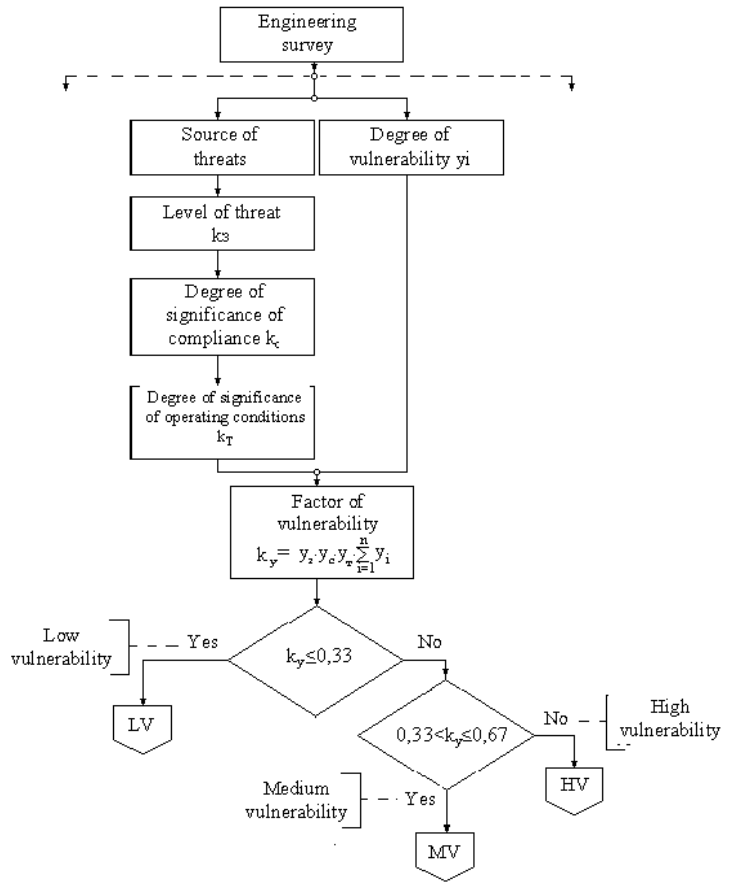

Fig. 1. Algorithm of taking account of risks of damages (determination of building vulnerability) 
- During the stage of designing threats for new and/or existing buildings as well as buildings located in the area affected by the new construction are determined on the basis of the engineering surveys. These findings shall be the basis for making a decision on a scope of controls and their operating conditions and the territory (see the figure). The algorithm of selection of control methods and measures, parameters and time intervals is depend on risks of damages, vulnerability of buildings and a territory of development (Fig. 2).

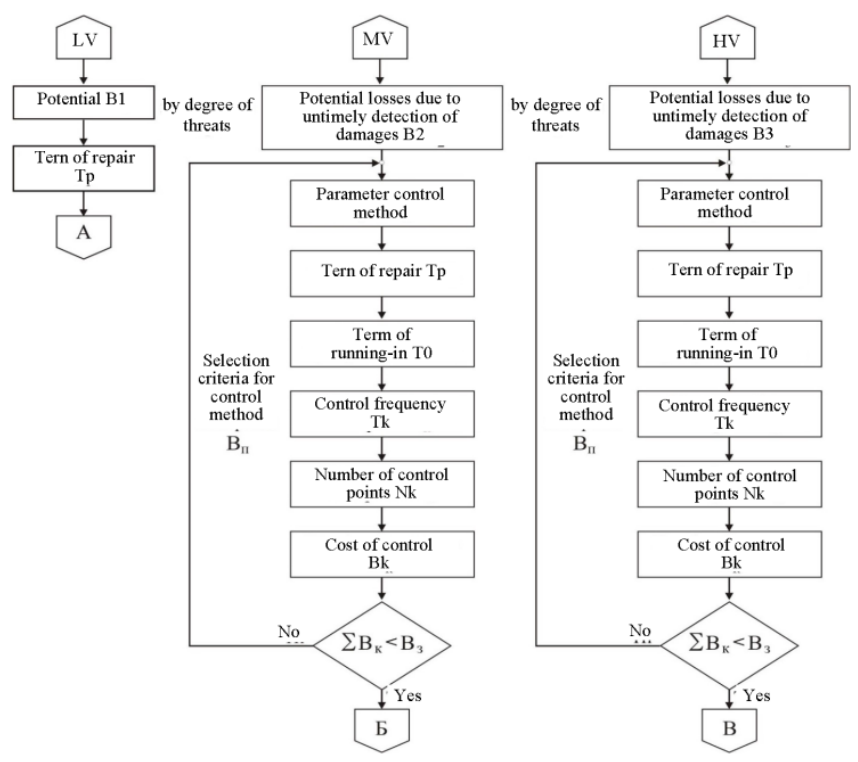

Fig. 2. Algorithm of selection of a method for examinations of building damages subject to a level of costs of potential losses (B1 - low, B2 - medium, B3 - high) for control versions:

$$
\text { (A-low, } \mathrm{B} \text { - medium, B - high) }
$$

In a case of low vulnerability (LV) control measures are not taken. Scheduled visual inspections and regular repairs are carried out. The frequency of repairs of the building is determined on the basis of its life cycle duration and predictable det $\epsilon$ Nion. In cases of medium and high vulnerability (MV, HV) the economic losses due to damages in the building are estimated before the selection of control methods. Costs of the control measures for variants A, Б, B against the potential $\mathrm{Y}$; are estimated, the frequency of measures and other technical and organizational indices are 
determined. The algorithms of measurement work during operation of buildings for variants A, Б, B are presented in Figs. 3-4.

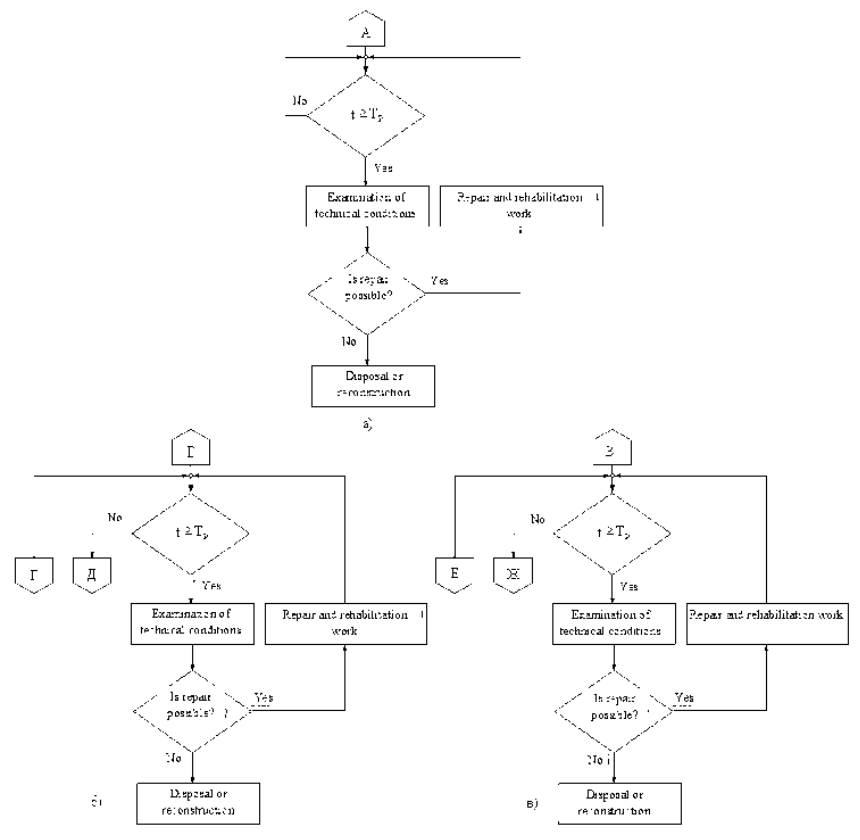

Fig. 3. shows the algorithm of arrangement of measurement work in the cases of low, medium or high vulnerabilities

Fig. 3. Algorithm of arrangement of measurement work during operation of buildings subject to design (A) values of listed factors and frequency of measurements, their changes (Б) according to variants $Д$ and $\Gamma$; changes (B) according to variants $\mathrm{E}$ and $Ж$ subject to a degree of object vulnerability

For variant A operations are carried out in a usual mode. If the term of operation has run up to the design term of repair $\left(T_{p}\right)$ examinations are carried out and their results are taken into account when a decision on a scope and composition of repairs is made. After completion of the repair work the building is continued to be under operation or, in a case when the serviceability has not been restored a decision on rehabilitation or disposal of the building is made. For medium or high vulnerability the building is operated in the same manner as for low vulnerability subject to possible changes in the frequency of measurements or the number of controlled 
parameters for higher degrees of vulnerability. The algorithm of such work is shown in Fig. 4.

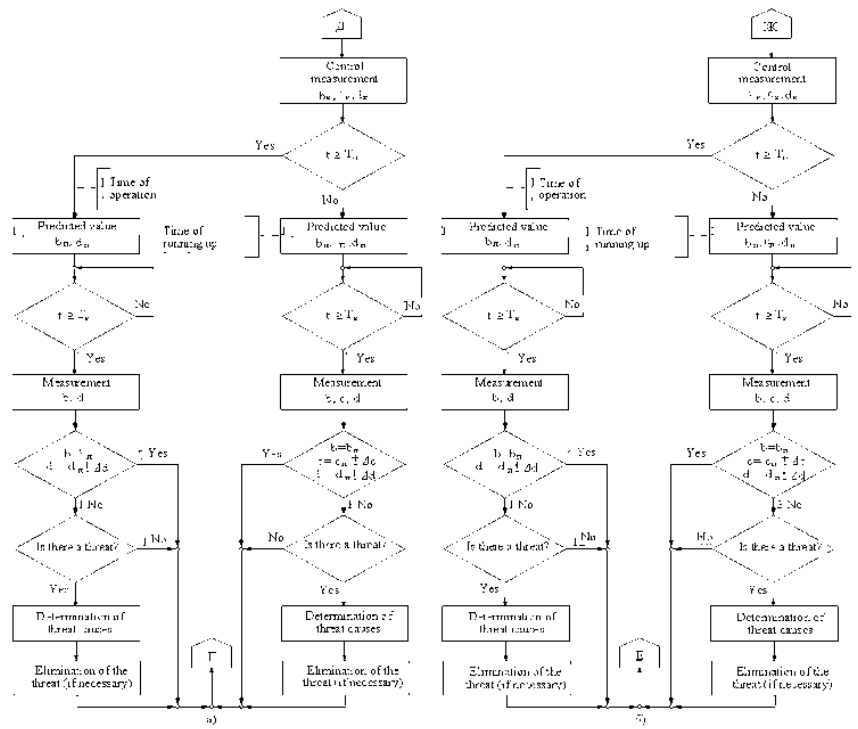

Fig. 4. Algorithm of arrangement of measurement work subject

to the object conditions under medium and high vulnerability (changes in the list of factors according variant Д and the frequency of measurements according variant $\Gamma$ )

Under medium vulnerability (variant Б) in the period of time before the term of established frequency of repair work $\left(T_{p}\right)$ the measurements are carried out (for the list of factors by variant Д) with the frequency (by variant $\Gamma$ ) established in designing. Under high vulnerability (variant B) the number of parameters may be more (variant $Ж$ ) and the frequency may be less (variant E). For automated systems the measurements will be carried out permanently.

The control operations begin with the measurement of parameters' initial values which will be used for forecasting. From the start of the building operation the processes of running up and initial subsidence begin. The term of initial subsidence $\left(T_{o}\right)$ is determined by soil properties. When the term $\left(T_{o}\right)$ is over the parameters specified in the project are checked and their predicted values are determined. When the control term $\left(T_{k}\right)$ is over, the building's parameters are compared with the predicted ones. If they are in 
accordance the control operations shall be continued as usual. If the parameters are at variance with the predicted ones causes of deviations shall be analyzed and preventive measures shall be taken. When the term $\left(T_{o}\right)$ is not over, in addition to the planned parameters the building's initial subsidence values shall be checked.

Losses due to untimely detection of damages are determined by estimation of risks for some territories, buildings or structures that are similar by their natural and man-caused conditions as well as geological threats sequentially. For them a warning period (the time interval for which the estimation of potential negative consequences is made) that equals the building service life without any repairs is established.

Risk of economic losses due to damages of building $B_{3}$ is established with due account of a negative effect of threat ${ }^{10}$ by formula

$$
\mathrm{B}_{3}=\mathrm{P}_{3} \cdot \mathrm{V}_{3} \cdot \mathrm{B}_{6} \cdot \mathrm{T}_{\text {заг }},
$$

where $P_{3}=\frac{T_{\text {zar }}}{T_{c}}$ is the probability of damages for the service life time;

$\mathrm{T}_{3 a r}=\mathrm{T}_{\mathrm{p}}$ is the time of probable damages (the term of next repair and restoration work);

$\mathrm{T}_{\mathrm{c}}$ is the building's service life;

$\mathrm{V}_{3}$ is the building's economic vulnerability to damages, 1/year, it shall be determined in accordance with ${ }^{9}$ subject to relations (1-3);

$\mathrm{B}_{\sigma}$ is the building cost at the beginning of the process.In estimating the economic losses for buildings which are historical landmarks the cost of objects in formula (4) is recommended to be replaced by the cost of their rehabilitation. The risk of general economic losses due to damages of buildings and structures is determined as a sum of losses due to individual risks. In estimating risks at the stage of designing (for example for underflooding) the economic vulnerability may be determined according to ${ }^{9}$ subject to relationships (4-5) and Tables 1-2.

Table 1

Mean values of economic vulnerability for underflooding processes

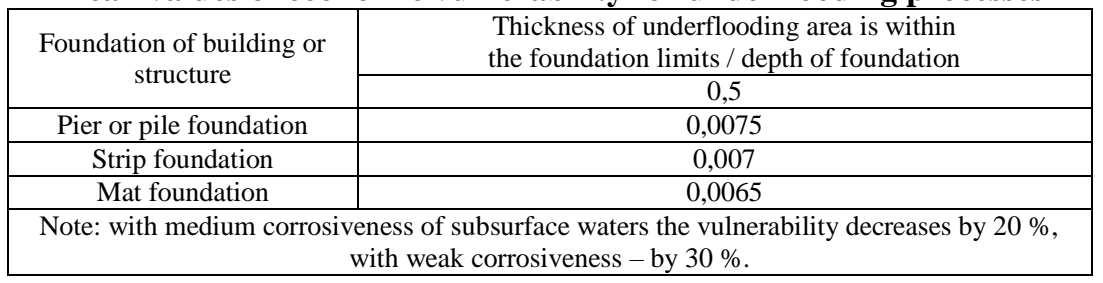

${ }^{10}$ Recommendations on estimation of geological risks in the territory of the city of Moscow 
Mean values of economic vulnerability for subsidence of bases due to geological threats

\begin{tabular}{|c|c|c|}
\hline \multirow{2}{*}{ Buildings and structures } & \multirow{2}{*}{ Subsidence, $\mathrm{cm}$} & Subsidence area / total area of foundations, $\mathrm{m}^{2}$ \\
\cline { 3 - 3 } & $20 \div 50$ & 0,5 \\
\hline Frame & $20 \div 50$ & 0,30 \\
\hline Frameless reinforced & $30 \div 50$ & 0,14 \\
\hline Frameless plain & $30 \div 50$ & 0,05 \\
\hline Monolithic & 0,005 \\
\hline
\end{tabular}

The economic losses are determined with due account of vulnerability $\mathrm{k}_{\mathrm{y}}$ and the physical deterioration of building

$$
\mathrm{B}_{3}=\mathrm{k}_{\mathrm{y}} \cdot\left(1-\mathrm{k}_{\text {зн }}\right) \cdot \sum_{\mathrm{i}=1}^{\mathrm{n}} \mathrm{B}_{3 \mathrm{i}},
$$

where $\mathrm{B}_{3 \mathrm{i}}$ is the economical losses due to the $\mathrm{i}^{\text {th }}$ threat;

$\mathrm{n}$ is the number of threat factors;

$$
\mathrm{k}_{\text {зн }}=\sum_{\mathrm{i}=1}^{\mathrm{m}} \mathrm{k}_{\text {зні }} \cdot \mathrm{k}_{\text {вві }} ;
$$

$\mathrm{k}_{\text {зні }} \quad$ is physical deterioration of the $\mathrm{i}^{\text {th }}$ structure;

$\mathrm{k}_{\text {вві }} \quad$ is the coefficient of restored cost of the $i^{\text {th }}$ structure;

$\mathrm{m}-$ is the number of damaged structures in the building.

During examinations just after construction work $\mathrm{k}_{\text {нН }}=1$.

\section{Principles of determination}

\section{of a scope of examinations for deformations}

The principles of determination of a scope of examinations for deformations are presented with due account of the vulnerability criterion ${ }^{11}$. The parameters that affect the degree of vulnerability ${ }^{4,12,13}$ are as follows: type of underground structure, degree of building deterioration; type of foundation, coefficient of slope stability, lithologic rock units, slope steepness, groundwater conditions. Underfloodings and vibrations are causes

${ }^{11}$ Tishin V.G. Fuzzy logic presentation of estimation of vulnerability of buildings and structures during designing and long operation under conditions of uncertainty / V.G. Tishin // Proceedings of Samara Center of the Russian Academy of Sciences. - 2011. - V. 13. - No. 4. P. 1034-1040.

${ }^{12}$ GOST R 22.8.09-2014. Safety in emergencies. Requirements to safety, risk, and damage levels estimation at underflooding of urban and industrial areas. - M. : Standartinform, 2015.

${ }^{13}$ Ruban N.N. Estimation of parameters of dynamic impacts from transport sources under conditions of the city of Dnepropetrovsk / Prospects of development of construction technologies : conf. publ. - 2007. - P. 86-95. 
of the increased probability of failures. When the parameters act jointly the numerical estimation of the degree of their joint influence is rather difficult as there is no any established criterion. Therefore this estimation of the building vulnerability has been carried out by the method of expert polling ${ }^{14}$. The values of the maximum possible degree of vulnerability to the factors of natural nature are shown in Table 3 .

Table 3

\section{Degree of building vulnerability}

\section{with due account of the factors of natural nature}

\begin{tabular}{|c|c|c|c|c|}
\hline Parameter & $\begin{array}{c}\text { Coefficient of } \\
\text { slope stability }\end{array}$ & $\begin{array}{c}\text { Lithologic rock } \\
\text { units }\end{array}$ & $\begin{array}{c}\text { Slope } \\
\text { steepness }\end{array}$ & $\begin{array}{c}\text { Groundwater } \\
\text { conditions }\end{array}$ \\
\hline Parameter code & $\mathrm{y} 1$ & $\mathrm{y} 2$ & $\mathrm{y} 3$ & $\mathrm{y} 4$ \\
\hline $\begin{array}{c}\text { Degree of } \\
\text { vulnerability }\end{array}$ & 0,30 & 0,21 & 0,31 & 0,18 \\
\hline
\end{tabular}

Parameters of building bases that affect their degree of vulnerability ${ }^{8}$ are shown in Table 4.

Table 4

Parameters of building bases

\begin{tabular}{|c|c|c|}
\hline Code & Designation of parameter & $\begin{array}{c}\text { Degree of } \\
\text { vulnerability }\end{array}$ \\
\hline \multirow{4}{*}{ y1 } & \multicolumn{2}{|l|}{ Coefficient of stability } \\
\hline & 1,25 & 0,10 \\
\hline & 1,20 & 0,20 \\
\hline & $>1,15$ & 0,30 \\
\hline \multirow{4}{*}{ y2 } & \multicolumn{2}{|l|}{ Lithologic rock units } \\
\hline & Silicified claystones, siltstones, sandstones & 0,07 \\
\hline & Marls with layers of marly siltstones, claystones, sandstones & 0,14 \\
\hline & $\begin{array}{l}\text { Marls with layers of sandstones, calciferous claystones with layers of } \\
\text { sandstones }\end{array}$ & 0,21 \\
\hline \multirow{4}{*}{ y3 } & \multicolumn{2}{|l|}{$\begin{array}{ll}\text { Slope steepness, degr. } \\
\end{array}$} \\
\hline & $0 \div 2$ & 0,10 \\
\hline & $2 \div 10$ & 0,21 \\
\hline & $10 \div 15$ and more & 0,31 \\
\hline \multirow{4}{*}{ y4 } & \multicolumn{2}{|l|}{ Groundwater conditions } \\
\hline & Absence of underground water & 0,06 \\
\hline & Sporadic expansion of underground water & 0,12 \\
\hline & Constant level of underground water & 0,18 \\
\hline
\end{tabular}

To take account of effects of underfloodings and vibrations in a draft plan of protective measures Table 5 shows data that characterize parameters of underflooding due to networks of water utilities ${ }^{12}$.

\footnotetext{
${ }^{14}$ Litvak B.G. Expert estimation and decision making / B.G. Litvak. - M. : Patent, 1996
} 
Characteristics of water utilities

\begin{tabular}{|c|c|c|c|}
\hline \multirow{2}{*}{$\begin{array}{c}\text { Parameter of water utilities } \\
\text { and water basins } \\
\text { (coefficient of significance), k3H }\end{array}$} & \multicolumn{3}{|c|}{$\begin{array}{c}\text { Coefficient of significance, } \\
\text { (value of parameter) }\end{array}$} \\
\cline { 2 - 4 } & high & medium & low \\
\hline Density of water utilities, $\mathrm{m} / \mathrm{ha}\left(k_{u}\right)$ & $\begin{array}{c}\text { more than } 500 \\
(1,2)\end{array}$ & $\begin{array}{c}400 \div 500 \\
(1,1)\end{array}$ & $\begin{array}{c}\text { less than } 400 \\
(1,0)\end{array}$ \\
\hline $\begin{array}{c}\text { Degree of deterioration of water utilities, } \\
\%,\left(k_{3}\right)\end{array}$ & $\begin{array}{c}\text { more than } 50 \\
(1,2)\end{array}$ & $\begin{array}{c}35 \div 50 \\
(1,1)\end{array}$ & $\begin{array}{c}\text { less than } 35 \\
(1,0)\end{array}$ \\
\hline $\begin{array}{c}\text { Distance from a natural source of } \\
\text { underflooding, } \mathrm{m},\left(k_{b}\right)\end{array}$ & $\begin{array}{c}\text { less than } 50 \\
(1,2)\end{array}$ & $\begin{array}{c}50 \div 200 \\
(1,1)\end{array}$ & $\begin{array}{c}\text { more than } 200 \\
(1,0)\end{array}$ \\
\hline
\end{tabular}

Effects of degrees of building compliance on factors of vulnerability are shown in Table 6.

Table 6

Effects of degrees of compliance on factors of
\begin{tabular}{|c|c|}
\hline Characteristic & Value kc \\
\hline degree of compliance CC1 & 0,9 \\
\hline degree of compliance CC2 & 1,0 \\
\hline degree of compliance CC 3 & 1,1 \\
\hline
\end{tabular}

Table 7 shows data that characterize sources of vibrations and coefficients of significance of these parameters with due account of the results ${ }^{13}$.

Table 7

Parameters of vibration sources

\begin{tabular}{|c|c|c|c|}
\hline \multirow{2}{*}{$\begin{array}{c}\text { Parameter of vibration sources } \\
\text { (coefficient of significance), k3H }\end{array}$} & \multicolumn{3}{|c|}{$\begin{array}{c}\text { Degree of significance, } \\
\text { (parameter value) }\end{array}$} \\
\cline { 2 - 4 } & high & medium & low \\
\hline Distance from a railway line, $\mathrm{m}\left(k_{b 3}\right)$ & $\begin{array}{c}\text { less than } 5 \\
(1,2)\end{array}$ & $\begin{array}{c}5 \div 200 \\
(1,1)\end{array}$ & $\begin{array}{c}\text { more than } 200 \\
(1,0)\end{array}$ \\
\hline Distance from a tramway line, $\mathrm{m}\left(k_{b 3}\right)$ & $\begin{array}{c}\text { less than } 5 \\
(1,2)\end{array}$ & $\begin{array}{c}5 \div 200 \\
(1,1)\end{array}$ & $\begin{array}{c}\text { more than } 200 \\
(1,0)\end{array}$ \\
\hline Distance from a Metro line, $\mathrm{m}\left(k_{b u}\right)$ & $\begin{array}{c}\text { less than } 5 \\
(1,2)\end{array}$ & $\begin{array}{c}5 \div 100 \\
(1,1)\end{array}$ & $\begin{array}{c}\text { more than } 100 \\
(1,0)\end{array}$ \\
\hline Distance from a highway, $\mathrm{m}\left(k_{b a}\right)$ & $\begin{array}{c}\text { less than } 5 \\
(1,2)\end{array}$ & $\begin{array}{c}5 \div 50 \\
(1,1)\end{array}$ & $\begin{array}{c}\text { more than } 50 \\
(1,0)\end{array}$ \\
\hline
\end{tabular}

The factor of building vulnerability to slides is calculated according to relationship (7) with the use of the data shown in Tables 4-7.

For further analysis and application the total vulnerability is divided into three degrees: high $\left(y_{i}\right)$, medium $\left(0,67 \cdot y_{\mathrm{i}}\right)$ and low $\left(0,33 \cdot \mathrm{y}_{\mathrm{i}}\right)$. For estimation 
of the total vulnerability the factor of vulnerability $k_{y}$, which equals a sum of the building vulnerabilities to some parameters, has been used

$$
\mathrm{k}_{\mathrm{y}}=\sum_{\mathrm{i}=1}^{\mathrm{n}} \mathrm{y}_{\mathrm{i}} \text {, at } 0 \leq \mathrm{k}_{\mathrm{y}} \leq 1
$$

where $y_{i}$ is the numerical value of vulnerability to the $i^{\text {th }}$ factor of influence;

$\mathrm{n}$ is the number of factors of influence on the object.

Probability of damages depends on not only the building vulnerability but also the characteristics of the threat source. The factors of influence may be separately estimated in every particular case as a coefficient of significance $k_{3}$ for the resulting factor of vulnerability.

To take account of a degree of building compliance let's adopt a value of the coefficient of influence on vulnerability according to Table 6 . Then the coefficient of building vulnerability $k_{\mathrm{y} \sigma}$ to a particular factor may be determined as

$$
\mathrm{k}_{\mathrm{y} \sigma}=\mathrm{k}_{\mathrm{c}} \cdot \mathrm{k}_{3} \cdot \mathrm{k}_{\mathrm{y}},
$$

where $\mathrm{k}_{\mathrm{ci}}$ is the coefficient of influence of a degree of building compliance;

$\mathrm{k}_{3}$ is the coefficient of significance (power) of a threat source;

$\mathrm{k}_{\mathrm{y}}$ is the coefficient of vulnerability that is taken according to (8).

When there are a number of threats they shall be considered separately and a maximum or total value $\mathrm{k}_{3}=\mathrm{k}_{3}^{\max }$ shall be taken for estimation.

To make a decision on a necessity of performing examinations and their scope let's determine a class of building vulnerability to a particular risk factor according to relationships (1-3).

The coefficient $\mathrm{k}_{\mathrm{y} \sigma}$ can take values that exceed 1,0 when a coefficient of threat significance, a degree of compliance etc. are taken into account. The further development of processes may be predicted on the basis of the examination results. The frequency of checks is determined by a maximum rate of changes in geometrical parameters of buildings, structures and development areas (deformations, subsidences, slides) subject to ratios of costs of measurements and 


\section{Selection of a system and scope of instrumental examinations of underfloodings}

Negative consequences of underflooding processes are subsidences and depressions in the earth surface due to soil wetting and compacting when the level of ground water rises. As a result the corrosive destruction of foundations and lower parts of surface structures occurs and increases the rate of deterioration and deformation of a building as a whole and leads to flooding of basements, lift shafts, underground structures and utilities of shallow locations. Risks of damages are estimated on the basis of the data of engineering surveys. In addition to estimation of potential causes of damages the estimation of risks shall include the estimates of vulnerability of buildings and nearby areas ${ }^{8}$. The method uses the known criteria of estimation of underflooding effects on building structures with the use of the factor of vulnerability that characterizes a degree of influence on buildings and structures. On the basis of the factor of vulnerability a degree of underflooding threat for buildings may be estimated and a decision on necessity of instrumental examinations or permanent automated monitoring can be made.

Input data for selection of a measurement system and designing a procedure of measurement work under operation are as follows: design solutions and construction materials which affect the vulnerability of a building to underflooding; soil features to change its characteristics after being underflooded; sources of potential underflooding whose presence is a threat to the building; the building's operating conditions whose deterioration increases its vulnerability.

An attempt of quantitative estimation of the degree of risks' negative effects demonstrates a need for characterization of an emerged threat. For this purpose the method of expert assessment has been applied. The method has been described in the previous paragraph. The following factors have been ranked as the highest: a degree of building deterioration, foundation type, bearing capability of soils, level of subsurface water (Table 8).

Table 8

Degree of building vulnerability under underflooding

\begin{tabular}{|c|c|c|c|c|}
\hline Parameter & $\begin{array}{c}\text { Degree of building } \\
\text { deterioration }\end{array}$ & $\begin{array}{c}\text { Type of } \\
\text { foundation }\end{array}$ & $\begin{array}{c}\text { Bearing } \\
\text { capability of } \\
\text { soils }\end{array}$ & $\begin{array}{c}\text { Level of } \\
\text { subsurface } \\
\text { water }\end{array}$ \\
\hline Parameter code & $\mathrm{y} 1$ & $\mathrm{y} 2$ & $\mathrm{y} 3$ & $\mathrm{y} 4$ \\
\hline Degree of vulnerability & 0,22 & 0,17 & 0,33 & 0,28 \\
\hline
\end{tabular}


Tables 9-10 show buildings and bases parameters that affect a degree of vulnerability under underflooding. The degree of low vulnerability is defined as $0,67 \cdot y_{i}$ and $0,33 \cdot y_{i}$ of the maximum vulnerability.

To estimate the building vulnerability to parameters that threaten with damages the factor of building vulnerability $\mathrm{k}_{\mathrm{y}}$ represented by a sum of the factors of vulnerability to individual parameters is used

$$
\mathrm{k}_{\mathrm{y}}=\sum_{\mathrm{i}=1}^{\mathrm{n}} \mathrm{y}_{\mathrm{i}} \text {, at } 0 \leq \mathrm{k}_{\mathrm{y}} \leq 1
$$

\section{Table 9}

Parameters of buildings

\begin{tabular}{|l|c|c|}
\hline Code & Degree of vulnerability & Designation of parameter \\
\hline \multirow{3}{*}{ y1 } & \multicolumn{2}{|c|}{ Degree of building deterioration } \\
\cline { 2 - 3 } & 0,07 & less than $15 \%$ \\
\cline { 2 - 3 } & 0,15 & $15 \div 50 \%$ \\
\hline \multirow{3}{*}{ y2 } & 0,22 & more than $50 \%$ \\
\cline { 2 - 3 } & \multicolumn{2}{|c|}{ Type of foundation } \\
\cline { 2 - 3 } & 0,06 & pile \\
\cline { 2 - 3 } & 0,11 & mat \\
\hline
\end{tabular}

Probability of damages depends on not only the building vulnerability but also the properties of the source of threat. Such properties may be a distance of the building from the source or a parameter that characterizes the threat source's power. These factors may be estimated separately as a coefficient of significance $k_{3}$ for the resulting factor of vulnerability.

Table 10

\section{Parameters of soils}

\begin{tabular}{|c|c|c|}
\hline Code & Degree of vulnerability & Designation of parameter \\
\hline \multirow{4}{*}{ y3 } & \multicolumn{2}{|c|}{ Decrease in soil bearing capability } \\
\cline { 2 - 3 } & 0,11 & $<10 \%$ \\
\cline { 2 - 3 } & 0,22 & $10 \div 30 \%$ \\
\hline \multirow{4}{*}{ y4 } & 0,33 & $>30 \%$ \\
\cline { 2 - 3 } & \multicolumn{2}{|c|}{ Depth of subsurface water level with reference to earth surface, $\mathrm{m}$} \\
\cline { 2 - 3 } & 0,09 & $>2$ \\
\cline { 2 - 3 } & 0,19 & $1 \div 2$ \\
\hline
\end{tabular}

To take account of a degree of building compliance the coefficient of influence on vulnerability is adopted according to Table 11 . 
Table 11

Effect of degrees of building compliance on factors of vulnerability

\begin{tabular}{|l|c|c|}
\hline Designation & Value & Characteristic \\
\hline \multirow{3}{*}{$\mathrm{kc}$} & 0,9 & degree of compliance CC1 \\
\cline { 2 - 3 } & 1,0 & degree of compliance CC2 \\
\cline { 2 - 3 } & 1,1 & degree of compliance CC3 \\
\hline
\end{tabular}

In such a case a factor of vulnerability $\mathrm{k}_{\mathrm{y} 6}$ to a specific parameter of influence may be determined by relationship (7) where $\mathrm{k}_{\mathrm{y}}$ is a factor of vulnerability that is determined by relationship (8).

When a number of threats exist they shall be examined individually and the maximum value $k_{3}=k_{3}^{\max }$ shall be taken. The data on parameters of underflooding sources due to water utilities networks ${ }^{15}$ are shown in Table 12. The factor of building vulnerability to underflooding is calculated by formula (8) with the use of values shown in Tables 9-12.

A decision on a need for examinations and their scope is made with due account of relationships (1-3).

Table 12

Characteristics of water utilities

\begin{tabular}{|c|c|c|c|}
\hline \multirow{2}{*}{$\begin{array}{c}\text { Parameter of water utilities and water basins } \\
\text { (coefficient of significance), k3H }\end{array}$} & \multicolumn{3}{|c|}{$\begin{array}{c}\text { Coefficient of significance, } \\
\text { (value of parameter) }\end{array}$} \\
\cline { 2 - 4 } high & medium & low \\
\hline Density of water utilities, $\mathrm{m} / \mathrm{ha}\left(\mathrm{k}_{\mathrm{II}}\right)$ & $\begin{array}{c}\text { more than } 500 \\
(1,2)\end{array}$ & $\begin{array}{c}400 \div 500 \\
(1,1)\end{array}$ & $\begin{array}{c}\text { less than } 400 \\
(1,0)\end{array}$ \\
\hline Degree of deterioration of water utilities, $\%,\left(\mathrm{k}_{3}\right)$ & $\begin{array}{c}\text { more than } 50 \\
(1,2)\end{array}$ & $\begin{array}{c}35 \div 50 \\
(1,1)\end{array}$ & $\begin{array}{c}\text { less than } 35 \\
(1,0)\end{array}$ \\
\hline Distance from a natural source of underflooding, \\
$\mathrm{m},\left(\mathrm{k}_{\mathrm{B}}\right)$ & $\begin{array}{c}\text { less than } 50 \\
(1,2)\end{array}$ & $\begin{array}{c}50 \div 200 \\
(1,1)\end{array}$ & $\begin{array}{c}\text { more than } \\
200 \\
(1,0)\end{array}$ \\
\hline
\end{tabular}

\section{Selection of a system and scope of instrumental examinations of vibrations}

The method takes data on vibrations, their effects on buildings and factors of vulnerability into account. Input data for designing solutions for instrumental measurements are as follows: design solutions and construction materials which affect the vulnerability of a building to vibrations; soil capabilities to transfer vibrations to building structures; sources of vibrations

${ }^{15}$ Hryhorovskiy P.Ye. Selection of optimal methods for monitoring of operating conditions of building structures with the use of utility functions / P.Ye. Hryhorovskiy, N.P. Chukanova // New technologies in construction : coll. of sci. and tech. articles - K. : Publ. «Lira-K», 2014. Issue 27-28. - P. 21-24 
which threaten to disturb operating conditions of buildings; the building's operating conditions whose deterioration increases building vulnerability.

The main sources of man-caused vibrations in urban development areas are rail transport lines (Metro, tram lines and railway tracks). The range of vibration frequencies at various points of building depends on a source of generation, properties of soil, through which the generated vibrations are transmitted to structures, and transfer properties of structures ${ }^{4,8}$. The level of vibrations depends on excitation frequency and may be varied from units to some hundreds of millimeters per second.

Threats of damages may be disclosed by indirect methods such as periodic observations of vibration frequencies and levels, examinations of building operating conditions, subsidences and inclinations. External manifestations of such threats at the initial stages may be unnoticeable, therefore they are considered unsafe and owing to difficulties of their timely detection they can cause significant damages.

The vulnerability to vibrations is characterized by a limit value of velocity $\mathrm{v}_{\mathrm{rp}}$, whish is determined for a vertical component of the peak value of velocity.

$$
\mathrm{V}_{\mathrm{rp}}=\mathrm{v}_{0} \cdot \mathrm{F}_{\mathrm{g}} \cdot \mathrm{F}_{\mathrm{b}},
$$

where $\mathrm{v}_{0}$ is the reference value of velocity, $20 \mathrm{~mm} / \mathrm{s}$;

$F_{g}$ is the correction for the type of soil at the site of constructed structure (Table 13);

$F_{b}$ is the correction for the type and design of building and foundation.

Table 13

Correction for type of soil $\mathbf{F}_{\mathrm{g}}$

\begin{tabular}{|c|c|}
\hline Characteristic of soil & $\mathrm{F}_{\mathrm{g}}$ \\
\hline Very soft soil, soft clay & 0,5 \\
\hline Clay, muddy soil with high content of moisture & 0,8 \\
\hline Sand, crushed stone, muddy soil & 1,0 \\
\hline Firm boulder clay, packed filling with crushed stone & 1,8 \\
\hline
\end{tabular}

The correction for a type of building $F_{\mathrm{B}}$ depends on a type and design of structure, construction material and a type of foundation; it is calculated by formula

$$
\mathrm{F}_{\mathrm{b}}=\mathrm{k}_{\mathrm{b}} \cdot \mathrm{k}_{\mathrm{m}} \cdot \mathrm{k}_{\mathrm{f}},
$$

where $\mathrm{k}_{\mathrm{b}}$ is the correction for a type and design of structure; 
$\mathrm{k}_{\mathrm{m}}$ is the correction for material of structure;

$\mathrm{k}_{\mathrm{f}}$ is the correction for a type of foundation (Tables 14-16).

A degree of vibration effect on vulnerability of buildings has been estimated as a function of the peak value of vibration velocity ${ }^{4}$ with the use of the method of expert estimation (Table 17).

Table 14

Correction for type and design of structure $k_{b}$

\begin{tabular}{|c|c|}
\hline Type of structure & $\mathrm{k}_{\mathrm{b}}$ \\
\hline Large structure (bridge, trestle) & 1,70 \\
\hline Office building, production building & 1,20 \\
\hline Residential building of general design & 1,00 \\
\hline $\begin{array}{c}\text { Building that is highly sensitive to vibrations (high-rise building, structure with } \\
\text { lengthy flights) }\end{array}$ & 0,65 \\
\hline Historic or destroyed buildings & 0,50 \\
\hline
\end{tabular}

Table 15

Correction for material of structure $k_{m}$

\begin{tabular}{|c|c|}
\hline Basic material & $\mathrm{k}_{\mathrm{m}}$ \\
\hline Reinforced concrete, steel, wood & 1,20 \\
\hline $\begin{array}{c}\text { Plain concrete, porous concrete block, brickwork, light perlite concrete and other } \\
\text { similar materials }\end{array}$ & 1,00 \\
\hline Porous autoclaved concrete block and other similar materials & 0,75 \\
\hline
\end{tabular}

Table 16

Correction for type of foundation $\mathbf{k}_{\mathbf{f}}$

\begin{tabular}{|c|c|}
\hline Type of foundation & $\mathrm{k}_{\mathrm{f}}$ \\
\hline Bank, shearwall, foundation post & 0,7 \\
\hline Spread foundation & 0,8 \\
\hline Floating pile & 0,9 \\
\hline Column pile & 1,0 \\
\hline
\end{tabular}

Estimation of factors of influence may be designated as a coefficient of significance $\mathrm{k}_{3 \mathrm{i}}$ that characterizes the effect of vibrations on the vulnerability to the $i^{\text {th }}$ source of vibrations.

Table 17

Factor of vulnerability to vibrations

\begin{tabular}{|c|c|c|}
\hline \multirow{2}{*}{ Code } & $\begin{array}{c}\text { Vertical component of the peak value } \\
\text { of vibration velocity, }\end{array}$ & Factor of vulnerability \\
\hline \multirow{3}{*}{$\mathrm{k}_{\mathrm{y}}$} & $\mathrm{v}<0,1 \cdot \mathrm{v}_{\mathrm{rp}}$ & 0,33 \\
\cline { 2 - 3 } & $0,1 \cdot \mathrm{v}_{\mathrm{rp}}<\mathrm{v}<0,8 \mathrm{v}_{\mathrm{rp}}$ & 0,67 \\
\cline { 2 - 3 } & $\mathrm{v} \geq 0,8 \cdot \mathrm{v}_{\mathrm{rp}}$ & 1,0 \\
\hline
\end{tabular}


To take account of a degree of building compliance in the factor of vulnerability $\left(\mathrm{k}_{\mathrm{y} \sigma}\right)$ let's take the coefficient of significance of the effect of degree of vulnerability $\left(\mathrm{k}_{\mathrm{c}}\right)$ according to Table 11 . Let's take the factor of building vulnerability $k_{y \sigma}$ to a specific parameter according to (7). If there are a number of threats the maximum (or total) value $k_{3}=k_{3 i}^{\max }$ is taken as an estimate of threat. The coefficients of significance have been determined by the expert polling. The factor of vulnerability to vibrations is calculated according to relationship (8) with the use of vibration velocity values and parameters of threats.

A decision on a need of examinations and their scope is made subject to relationships (1-3).

\section{Selection of a system and scope of instrumental examinations of slides}

Input data for selection of a system and designing a process of measurement work under presence of slide threats are as follows: stability of slopes and their steepness; conditions and geological composition of soil base; sources of underfloodings and vibrations that threaten with disruption of slope stability. Risks of damages are estimated on the basis of the data of the engineering surveys which have been designated for developing measures for reducing negative effects of geological processes, natural and man-caused emergencies. In addition to estimation of threats the estimation of risks of damages shall include the estimates of vulnerability of buildings and nearby areas.

The degree of building vulnerability depends on characteristics of the building as well as characteristics and conditions of the soil base. Parameters of buildings and development areas which affect the degree of vulnerability are as follows: type of underground structure, degree of building deterioration, type of foundation, coefficient of slope stability, lithologic rock units, slope steepness, groundwater conditions.

The expert polling has determined the maximum possible degree of vulnerability to slides (Table 18).

Table 18

Degree of building vulnerability to slides

\begin{tabular}{|c|c|c|c|c|}
\hline Parameter & $\begin{array}{c}\text { Coefficient of slope } \\
\text { stability }\end{array}$ & $\begin{array}{c}\text { Lithologic rock } \\
\text { units }\end{array}$ & $\begin{array}{c}\text { Slope } \\
\text { steepness }\end{array}$ & $\begin{array}{c}\text { Groundwater } \\
\text { conditions }\end{array}$ \\
\hline Parameter code & $\mathrm{y} 1$ & $\mathrm{y} 2$ & $\mathrm{y} 3$ & $\mathrm{y} 4$ \\
\hline Degree of vulnerability & 0,30 & 0,21 & 0,31 & 0,18 \\
\hline
\end{tabular}

Main parameters of buildings and bases which affect the degree of vulnerability to slides are shown in Table 19. For estimation of building 
vulnerability to factors that threaten with occurrence of slides the factor of building vulnerability $\mathrm{k}_{\mathrm{y}}$ has been used. This factor is a sum of degrees of vulnerability to individual factors according to (8).

To take account of the degree of building compliance let's adopt the value of the coefficient of influence on vulnerability according to Table 6 . The factor of building vulnerability $k_{y \sigma}$ to a particular risk factor may be determined by (7). If there are a number of threats they shall be examined separately and the maximum value $\mathrm{k}_{3}=\mathrm{k}_{3}^{\max }$ shall be taken as an estimate of threat.

Underfloodings and vibrations may be causes which increase probability of slides. At that one shall take into consideration that at the stage of designing all measures against landslides shall be provided. The data specified in ${ }^{16}$ characterize parameters of underflooding sources related to water utilities (Table 5) and parameters of vibration sources (Table 7). The factor of building vulnerability to slides is calculated according to (8) with the use of values shown in Tables 7, 12, 18, 19. A decision on a need of examinations and their scope is made subject to relationships (1-3).

Table 19

Parameters of slopes

\begin{tabular}{|c|c|c|}
\hline Code & Designation of parameter & $\begin{array}{c}\text { Degree of } \\
\text { vulnerability }\end{array}$ \\
\hline \multirow{4}{*}{ yl } & \multicolumn{2}{|l|}{ Coefficient of slope stability } \\
\hline & 1,25 & 0,10 \\
\hline & 1,20 & 0,20 \\
\hline & $>1,15$ & 0,30 \\
\hline \multirow{4}{*}{$y_{2}$} & \multicolumn{2}{|l|}{ Lithologic rock units } \\
\hline & Silicified claystones, siltstones, sandstones & 0,07 \\
\hline & Marls with layers of marly siltstones, claystones, sandstones & 0,14 \\
\hline & $\begin{array}{l}\text { Marls with layers of sandstones, calciferous claystones with layers } \\
\text { of sandstones }\end{array}$ & 0,21 \\
\hline \multirow{4}{*}{$y_{3}$} & \multicolumn{2}{|l|}{$\begin{array}{l}\text { Slope steepness, degr. } \\
\end{array}$} \\
\hline & $0 \div 2$ & 0,10 \\
\hline & $2 \div 10$ & 0,21 \\
\hline & $10 \div 15 \mathrm{i}$ and more & 0,31 \\
\hline \multirow{4}{*}{$y_{4}$} & \multicolumn{2}{|l|}{ Groundwater conditions } \\
\hline & Absence of underground water & 0,06 \\
\hline & Sporadic expansion of underground water & 0,12 \\
\hline & Constant level of underground water & 0,18 \\
\hline
\end{tabular}

${ }^{16}$ DBN V.1.1-25-2009. Protection against dangerous geological processes. Engineering protection of territories and structures against underflooding and flooding. - [Current version 2011-01-01]. - K. : Minregionbud of Ukraine, 2010 
Further development of slides may be forecasted on the basis of the results of examinations. The frequency of checks is determined by the maximum velocity of slides subject to the ratio of the costs of such checks and potential losses due to development of slide processes.

\section{CONCLUSIONS}

1. Potential losses due to untimely detection of damages are recommended to prevent by sequential estimations of risks of individual, similar to natural and man-caused conditions and geological threats for development areas with a term of warning (the time interval for which possible negative consequences are estimated) that is equal to the established service life of buildings and structures without any repair or rehabilitation work.

2. The method of determination of the optimal scope of instrumental examinations during operation of buildings and structures with due account of the criterion of vulnerability has been developed.

3. The main parameters of buildings and development areas that affect the degree of vulnerability are as follows: type of underground structure, degree of building deterioration, type of foundation, coefficient of slope stability, lithologic rock units, slope steepness, groundwater conditions. Natural and man-caused processes affect the emergence of failures. The most common and dangerous are landslides, underfloodings, subsidences, erosion, abrasion and karst. Their intensification occurs as a result of changes in temperature or subsurface water flows.

4. The method for selection of the system of instrumental examinations of underflooding during operation of buildings and structures has been developed.

5. The method for selection of the system of instrumental examinations of vibrations during operation of buildings and structures has been developed. A degree of influence of vibrations on building vulnerability as a function of the peak value of vibration velocity has been estimated by the method of expert estimation. The probability of damages depends on not only the building vulnerability but also the characteristics of threat source.

6. The method for selection of the system of instrumental examinations of landslides during operation of buildings and structures with due account of the vulnerability criterion has been developed. The input data for selection of a system and design of a process (composition, sequence of operations, scope, terms, labor intensity, costs) of measurement work during operation are as follows: stability and steepness of slopes where the building is located, conditions and geological composition of soil base, potential sources of underfloodings and vibrations, whose presence is a threat to stability of slopes. 


\section{SUMMARY}

Research into interactions between construction activities, surrounding territories and neighboring developed areas is an urgent problem when natural and man-caused processes are studied and coped with during construction and operation of buildings. Defects and damages of buildings that have not been detected in good time result in deformations. Their effects result in material, social and ecological losses. Therefore the prompt evaluation of building conditions, the forecasting of trends in development of defects and damages and the elaboration of measures on their stabilization or removal are very important. For that a mechanism of destruction and wearing of structural elements during construction and operation activities shall be understood and the opportunity of estimation of effects of environmental factors shall exist. For this purpose the objective data measured and collected with the use of instrumentation are vital. The work concerns with the principal natural and man-caused factors that affect the serviceability of buildings, in particular, deformations, landslides, underflooding and vibrations that have destructive effects on the operating availability of buildings and structures. The recommendations on determination of an optimal scope of instrumental measurements have been elaborated for such objects that are under construction or operation. Potential losses due to untimely detection of damages are recommended to prevent by sequential estimations of risks of individual, similar to natural and mancaused conditions and geological threats for development areas. The method of determination of the optimal scope of instrumental examinations during operation of buildings and structures with due account of the criterion of vulnerability has been developed. The methods for selection of estimation procedures have been developed: the system of instrumental examinations of underflooding during operation of buildings and structures; the system of instrumental examinations of vibrations during operation of buildings and structures; the system of instrumental examinations of landslides during operation of buildings and structures with due account of the vulnerability criterion. The main parameters of buildings that affect the degree of vulnerability are as follows: type of underground structure, degree of building deterioration, type of foundation, coefficient of slope stability, lithologic rock units, slope steepness, groundwater conditions. The most common and dangerous natural and man-caused processes are landslides, underfloodings, subsidences, erosion, abrasion and karst. Their intensification occurs as a result of changes in temperature or subsurface water flows. 


\section{REFERENCES}

1. National report on the state of man-caused and natural safety in Ukraine in 2014. The State Emergency Service of Ukraine. Kyiv, 2015. [Electronic resource] : access mode http://undicz.dsns.gov.ua/ua/Nacionalnadopovid-pro-stan-tehnogennoyi-ta- (in Ukrainian)

2. Recommendations on estimation of geological risks in the territory of the city of Moscow. - [Electronic resource] : access mode http://aquagroup.ru/normdocs/7677 (15.07.16). - Title on screen (in Russian)

3. SP 11-105-97 System of normative documents in the construction industry. Code of regulations on engineering surveys for the construction industry. Part II. Regulations on production of work in the regions of development of dangerous geological or engineering and geological processes. - [Electronic resource] : access mode : http://docs.cntd.ru/document/1200007405 (15.09.15). - Title on screen. (in Russian)

4. GOST R 52892-2007. Vibration and shock. Vibration of buildings. Measurement of vibration and evaluation of its effects on structure. - M. : Standartinform, 2008. $-20 \mathrm{p}$.

5. Osypov O.F. Construction under conditions of urban development. Experience and prospects / O.F. Osypov, I.T. Hladun // Urban and territorial planning : coll. sci.-techn. art. - K. : KNUBA, 2004. - No. 12. - P. 9.18. (in Ukrainian)

6. VSN 358-76 Instructions on pile driving near buildings and structures. - M. : TsBNTI, 1976. - 54 p. (in Russian)

7. Dudkin E.S. Dynamic effects of municipal transport movement on buildings and structures / E.S. Dudkin // Polzunov Bulletin. 2007. No. 1-2. - P. 30-32. (in Russian)

8. Methodic recommendations for estimation of risk and damage at underflooding of territories. - M., 2001. - 56 p. (in Russian)

9. Mikhailenko V.M., Hryhorovskyi P.Ye., Models and methods of information system for diagnostics of operating conditions of construction projects / V.M. Mikhailenko, I.V. Rusan, P.Ye. Hryhorovskyi, O.O. Terentiev, A.T. Sviderskiy, Ye.V. Horbatiuk. - K. : TsP «Komprynt». - 2018. - 225 p. (in Ukrainian)

10. Recommendations on estimation of geological risks in the territory of the city of Moscow. - [Electronic resource] : access mode http://aquagroup.ru/normdocs/7677 (15.07.16). - Title on screen. (in Russian)

11. Tishin V.G. Fuzzy logic presentation of estimation of vulnerability of buildings and structures during designing and long operation under conditions of uncertainty / V.G. Tishin // Proceedings of Samara Center of 
the Russian Academy of Sciences. - 2011. - V. 13. - No. 4. - P.1034-1040. (in Russian)

12. GOST R 22.8.09-2014. Safety in emergencies. Requirements to safety, risk, and damage levels estimation at underflooding of urban and industrial areas. - M. : Standartinform, 2015. - 42 p. (in Russian)

13. Ruban N.N. Estimation of parameters of dynamic impacts from transport sources under conditions of the city of Dnepropetrovsk / Prospects of development of construction technologies : conf. publ. - 2007. - P. 8695. (in Russian)

14. Litvak B.G. Expert estimation and decision making / B.G. Litvak. M. : Patent, 1996. - 271 p. (in Russian)

15. Hryhorovskiy P.Ye. Selection of optimal methods for monitoring of operating conditions of building structures with the use of utility functions / P.Ye. Hryhorovskiy, N.P. Chukanova // New technologies in construction : coll. of sci. and tech. articles - K. : Publ. «Lira-K», 2014. - Issue 27-28. P. 21-24. (in Ukrainian)

16. DBN V.1.1-25-2009. Protection against dangerous geological processes. Engineering protection of territories and structures against underflooding and flooding. - [Current version 2011-01-01]. - K. : Minregionbud of Ukraine, 2010. - 52 p. - (State building code of Ukraine). (in Ukrainian)

\section{Information about the author: \\ Hryhorovskyi P. Ye.,}

Doctor of Technical Sciences,

First Deputy Director for Science, State Enterprise 'Research Institute of Building Production named of V. S. Balitsky' (SE 'RIBP') 51, Lobanovskyi av., Kyiv, 03110, Ukraine 